\title{
Atmospheric Corrosion of Painted Galvanized and 55\%Al-Zn Steel Sheets: Results of 12 Years of Exposure
}

\author{
C. I. Elsner, ${ }^{1,2}$ P. R. Seré, ${ }^{1}$ and A. R. Di Sarlii ${ }^{1}$ \\ ${ }^{1}$ CIDEPINT, Centro de Investigación y Desarrollo en Tecnología de Pinturas (CICPBA-CCT CONICET-La Plata), \\ Avenida 52 s/n entre 121 y 122, B1900AYB La Plata, Argentina \\ ${ }^{2}$ Facultad de Ingeniería, Universidad Nacional de La Plata, Avenida 1 esq. 47, B1900TAG La Plata, Argentina
}

Correspondence should be addressed to A. R. Di Sarli, ardisarli@gmail.com

Received 28 July 2011; Accepted 1 November 2011

Academic Editor: Blanca M. Rosales

Copyright () 2012 C. I. Elsner et al. This is an open access article distributed under the Creative Commons Attribution License, which permits unrestricted use, distribution, and reproduction in any medium, provided the original work is properly cited.

\begin{abstract}
Zinc or 55\%Al-Zn alloy-coated steel sheets, either bare or covered by different painting systems, have been exposed for 12 years to the action of the urban atmosphere at the CIDEPINT station located in La Plata ( $34^{\circ} 50^{\prime}$ South, $57^{\circ} 53^{\prime}$, West), province of Buenos Aires, Argentina. The samples exposed surface was evaluated through periodical visual inspections, standardized adhesion tests, and electrochemical impedance measurements. The ambient variables monitored were average annual rains and temperatures, time of wetness, sulphur and chloride concentration, relative humidity, and speed and direction of the winds. It was found that in this atmosphere, the corrosion resistance of the bare $55 \% \mathrm{Al}-\mathrm{Zn} /$ steel sheets was higher than of the galvanized steel, and the polyurethane painting system was more protective than the alkyd and epoxy ones, which degraded after 6-7 years of exposure.
\end{abstract}

\section{Introduction}

Exposed to specific aggressive media, metal or alloy stability depends upon the protective properties of the surface film formed, because its chemical composition, conductivity, adherence, solubility, hygroscopicity, and morphological characteristics determine the film capacity to work as a controlling barrier [1]. In such a sense, steel galvanic protection by means of zinc or zinc alloys is a common example, owing not only to the fact that the zinc, being electrochemically more active than the steel, corrodes preferentially, but also to the barrier effect of the corrosion products precipitated on the metallic surface. In particular, the coatings based on zinc are widely used to protect steel structures against atmospheric corrosion [2], because of the protective properties afforded by an insoluble film of basic carbonate. However, if the exposure conditions are such that there is changes of the ambient variables like atmospheric conditions, UV radiation intensity, type and level of pollutants, wet-dry cycles, depletion of air but high humidity, or a medium containing strongly aggressive species like chloride or sulphate ions, the zinc could dissolve forming soluble, less dense, and scarcely protective corrosion products, which sometimes lead to localized corrosion [2-5]. This condition can be reached during the storage and transportation of galvanized steel sheets or when they are exposed to marine and/or industrial environments [6]. Aluminium coatings have overcome these two factors. Nevertheless, as they cannot provide cathodic protection to exposed steel in most environments, early rusting occurs at coating defects and cut edges; besides, these coatings are also subjected to crevice corrosion in marine environmental [7].

For years, many attempts to improve the corrosion resistance of zinc and aluminium coatings through alloying were carried out. Although the protective effect of combinations of these two elements was known, they were not used until the discovery that silicon inhibits the fast alloying reaction with steel [8]. Thus, the alloy commercially known as Galvalume or Zincalum arose, and its composition: $55 \% \mathrm{Al}, 1.6 \% \mathrm{Si}$, the rest zinc, was selected from a systematic study, providing an excellent combination of galvanic protection and low corrosion rate.

When a higher degree of protection of these metallic surfaces is of concern, properly chosen painting systems can provide a more effective corrosion-inhibiting barrier and also a better aesthetic appearance [9]. Some exposure conditions are so aggressive that both protective systems 
(metallic + organic coatings) must be applied to get longer effectiveness. Such a combination, referred to as a duplex system, has demonstrated a synergistic effect when compared to the individual coating systems. This better corrosion protection is attributed to the double action afforded by the zinc or $55 \% \mathrm{Al}-\mathrm{Zn}$ layer (cathodic protection + blockage of its defects by the corrosion products), and also by the pigmented paint system (barrier effect + steel corrosioninhibition) [10]. Besides, this duplex system requires less reconditioning and repairs of coating systems after transportation and assembly on site.

The mechanism responsible for the protective action of paint coatings is highly complex because it depends upon the simultaneous action of different factors. Irrespective of their intended function (functional, decorative, or protective), the paint must adhere satisfactorily to the underlying substrate $[11,12]$.

The organic film permeability is important in metallic substrate corrosion, since this property is directly connected to the permeation of environmental corrosion-inducing chemicals through the polymeric matrix, the chemical composition of the latter, and the presence of pores, voids, or other defects in the coating. It is important to note that particularly water and oxygen can permeate the film, at least to some extent, even if none of the intrinsic structural defects are present. For these reasons, the painted metal's resistance to degradation produced by weathering is a very important variable, since it defines the material's durability. Within this concept, the corrosion and resistance to weathering (degradation due to UV radiation, oxygen, humidity, etc.) are separately evaluated. The corrosion resistance depends upon the permeability (barrier effect) of the primer and galvanic layer as well as of the inhibitive capacity of the contained anticorrosive pigments. The weathering degradation (loss of gloss and/or adhesion, chalking, cracking, blistering, etc.) takes place at shorter times and depends mainly on the topcoat paint properties.

The still unsolved paint delamination or blistering problem, due to a bad bond at the substrate/paint interface, depends upon the chemical nature and crosslinking degree of the polymer as well as the metal substrate and its surface treatment [13]. In principle, paint adhesion can be improved by providing the substrate with a pretreatment layer, followed by applying a corrosion inhibiting primer + intermediate and/or topcoat paints. In line with this definition, the primer is considered the critical element in most paint systems because it is mainly responsible for preserving the metallic state of the substrate, and it must also anchor the total paint coating to the steel. Most coatings adhere to the metal via purely physical attractions (e.g., hydrogen bonds) that develop when two surfaces are brought closely together $[14,15]$. Paint vehicles with polar groups $(-\mathrm{OH},-\mathrm{COOH}$, etc. $)$ have good wetting properties and show excellent physical adhesion characteristics (epoxies, alkyds, oil paints, etc.). Much stronger chemically bonded adhesion is possible when the primer can actually react with the metal, as is the case of several pretreatments [16-18].

Paint life depends on several factors such as the metallic substrate, the selected paint system, and the paint-substrate interface [19]. Paint selection is generally based on the aggressive medium properties, while the metal treatment before painting has a substantial impact on the useful life of the selected system.

The susceptibility to degradation of painted metals is estimated by accelerated laboratory tests and natural atmospheric exposure for several years [20-31]. Although the extrapolation of accelerated test results do not compare linearly to the actual performance of the coatings in their service life, it can supply useful information related to the rate and form of the corrosion-inhibiting system degradation. In most cases, such information can help to improve the paint formulation and/or the painting scheme design. Consequently, a comparative evaluation of the protective performance of either bare or covered with three different painting systems is reported in this paper. The corrosion resistance of these samples was tested by exposure for 12 years to the action of the urban atmosphere at the CIDEPINT station located in La Plata ( $34^{\circ} 50^{\prime}$ South, $57^{\circ} 53^{\prime}$, West), province of Buenos Aires, Argentina.

The evolution of the samples exposed surface was evaluated through periodical visual inspections, adhesion tests according to the ASTM D-3359/09 standard, and electrochemical impedance measurements applied to samples immersed for $1 \mathrm{~h}$ in $0.5 \mathrm{M} \mathrm{Na}_{2} \mathrm{SO}_{4}$ solution. The ambient variables monitored were average annual rains and temperatures, time of wetness, sulphur and chloride concentration, relative humidity, and speed and direction of the winds.

\section{Experimental Details}

A total of 280 commercial-grade steel sheets $(15 \times 8 \times$ $0.2 \mathrm{~cm}$ ) hot-dip coated with zinc or $55 \% \mathrm{Al}-\mathrm{Zn}$ plates were used as the metallic substrate. They were degreased by immersion in $5 \% \mathrm{Na}_{2} \mathrm{CO}_{3}$ solution and then rinsed with distilled water to eliminate any possible surface contamination.

The commercial-grade protective painting systems (Table 1) were applied by brushing to maintain the same conditions for all the samples. After applying the painting system, the painted plates were placed in a dessicator cabinet at controlled temperature $\left(30 \pm 2^{\circ} \mathrm{C}\right)$ until completely dry. Next, measurements of dry film thickness (Table 1) were taken with an Elcometer 300 coating thickness gauge, using a bare sanded plate and standards of known thickness as references. Plates were exposed at $45^{\circ}$ from the horizontal and they were oriented East allowing a maximum insolation on them. The test site was formed by wooden structures, where the flat plates were set on. Location coordinates, meteorological data, atmospheric pollutants, time of wetness and corrosion category of the place of location according to ISO 9223 are given in Figure 1 and Tables 2 and 3, respectively. All environmentally data were available from the Seismology and Meteorological Department of the Astronomic and Geophysics Science Faculty of the National University of La Plata, placed very near CIDEPINT Station.

To check reproducibility, a total of 280 samples including bare or painted steel/zinc or steel/55\%Al-Zn sheets were exposed to natural weathering in La Plata station for 12 years. 
TABLE 1: Mean thicknesses $(\mu \mathrm{m})$.

\begin{tabular}{lcccc}
\hline Metal/paint system & Metallic coating & Primer & Topcoat & Total thickness \\
\hline S/Z/AS & $18 \pm 0.9$ & $22 \pm 0.9$ & $52 \pm 2.6$ & $92 \pm 4.5$ \\
S/ZA/AS & $20 \pm 0.9$ & $22 \pm 0.9$ & $52 \pm 2.6$ & $94 \pm 4.5$ \\
S/Z/ES & $18 \pm 0.9$ & $4 \pm 0.2$ & $87 \pm 2.6$ & $109 \pm 5.1$ \\
S/ZA/ES & $20 \pm 0.9$ & $4 \pm 0.2$ & $87 \pm 2.6$ & $11 \pm 5.1$ \\
S/Z/PS & $18 \pm 0.9$ & $4 \pm 0.2$ & $48 \pm 2.6$ & $70 \pm 3.5$ \\
S/ZA/PS & $20 \pm 0.9$ & $4 \pm 0.2$ & $48 \pm 2.6$ & $72 \pm 3.5$ \\
\hline
\end{tabular}

Note: S/Z/AS: galvanized steel/alkyd-based paint system; S/ZA/AS: steel/55\%Al-Zn alloy/alkyd-based paint system; S/Z/ES: galvanized steel/epoxy-based paint system; S/ZA/ES: steel/55\%Al-Zn alloy/epoxy-based paint system; S/Z/PS: galvanized steel/polyurethane-based paint system; S/ZA/PS: steel/55\%Al-Zn alloy/polyurethane-based paint system.

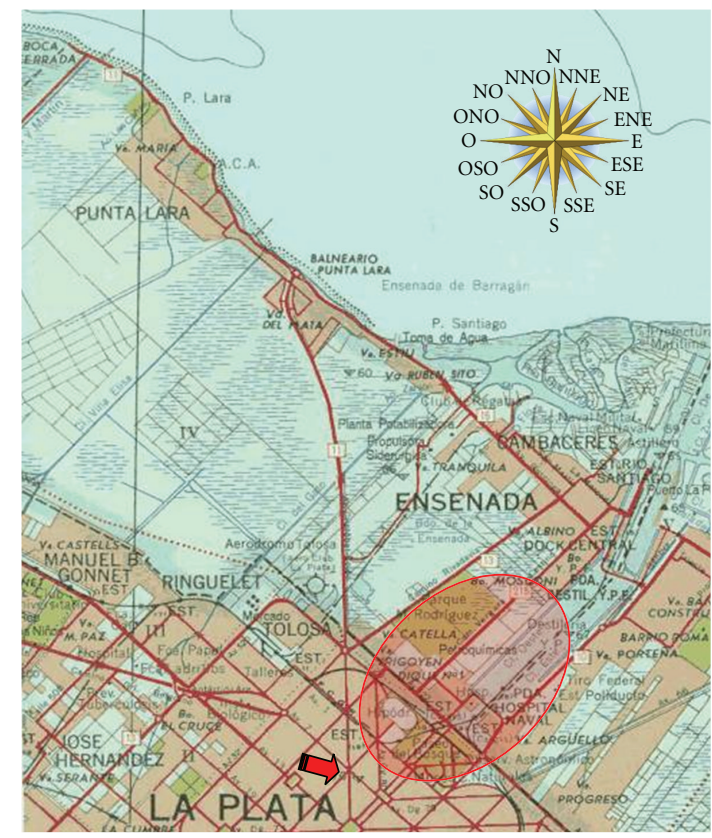

CIDEPINT station
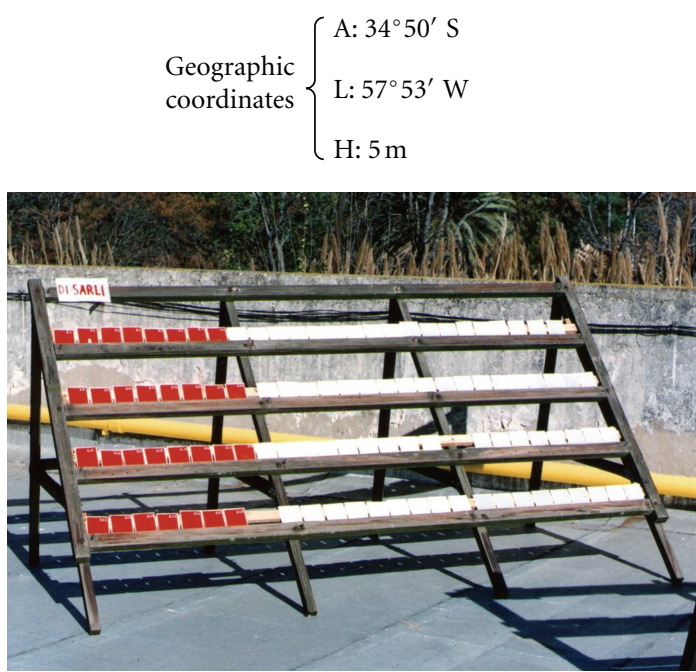

Industrial area

CIDEPINT station

Figure 1: Location of the CIDEPINT station in La Plata, Buenos Aires, Argentina.

The painted samples were build-up with the three painting systems mentioned in Table 1, and their edges were masked with a thick wax base coating to avoid edge effect.

Gravimetric determinations for measuring weight-loss of bare steel/metallic coating samples were carried out in triplicate for each material tested.

The visual inspections and samplings took place according to the following program: during the first year each 1st, 3rd, 6th, 9th, 12th month, and then each 2nd, 4th, 8th, and 12 th year. At the same times, adhesion tests according to the Test Tape ASTM D-3359/09 Standard on replicates of each type of painted samples were also performed.

2.1. Electrochemical Measurements. For the impedance measurements periodically carried out on other replicates of each type of samples, a cylindrical clamp-on acrylic (polymethyl methacrylate) cell was positioned on the painted panel by an
O-ring defining a surface area of $15.9 \mathrm{~cm}^{2}$. An aperture in the top of this three electrode electrochemical cell contained a Pt-Rh mesh counter-electrode with negligible impedance, oriented parallel to the working electrode (painted metal surface). A glass-linear Saturated $\mathrm{Hg} / \mathrm{HgSO}_{4}$ tipped Reference Electrode was positioned, together with the counterelectrode, close to the exposed painted steel surface panel. For further easy comparison with previous information, all the potential data in the text and figures were referred to the Saturated Calomel Electrode (SCE). Before the electrochemical impedance spectrum of each replicate was obtained, the sample was subjected to 1 hour of wetting in $0.5 \mathrm{M}$ $\mathrm{Na}_{2} \mathrm{SO}_{4}$ solution. Impedance spectra were obtained from a Solartron 1255 FRA coupled to a Solartron EI 1286 and a PC, all controlled by the Zplot software. Impedance spectra collected in the frequency range $10^{-2} \leq \mathrm{f}(\mathrm{Hz}) \leq 10^{6}$ were analyzed and interpreted on the basis of equivalent electrical 


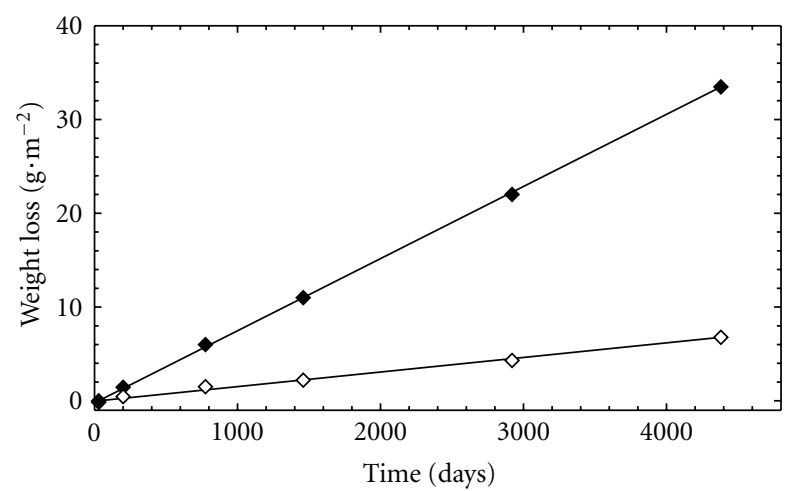

$\bullet \mathrm{S} / \mathrm{Z}$

$\diamond S / Z A$

FIGURE 2: Plots showing the time dependence of the weight loss suffered by the bare S/Z and S/ZA sheets.
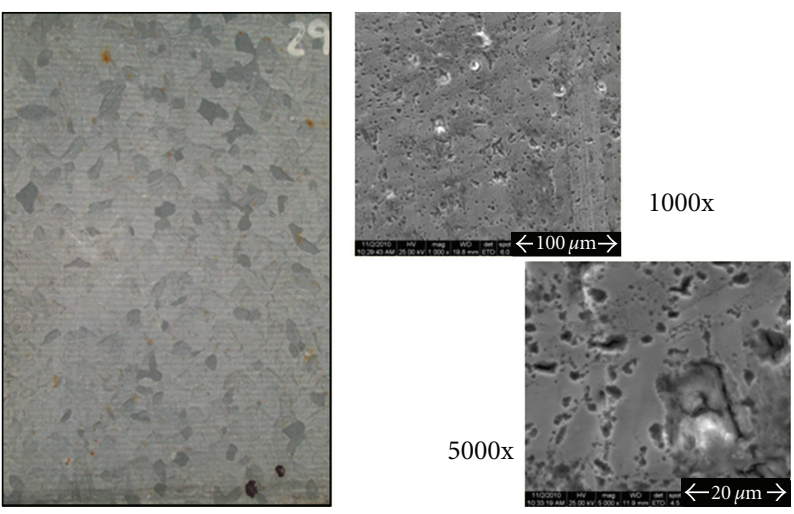

Galvanized steel

(a)
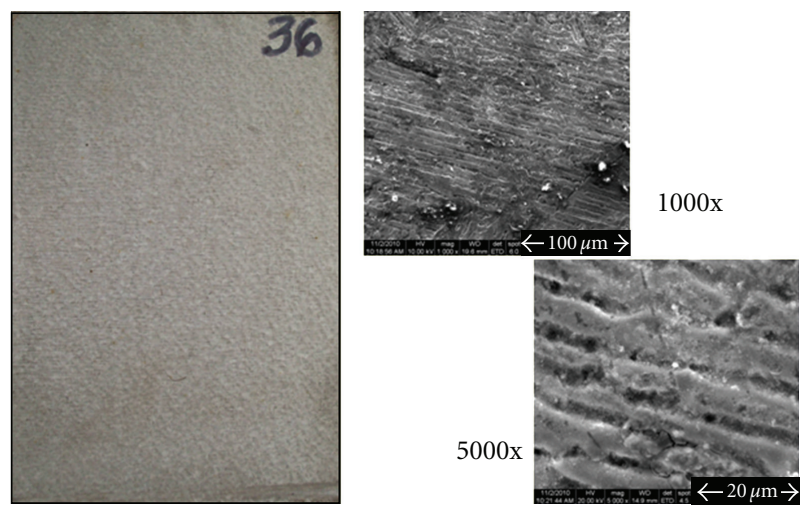

Steel $/ 55 \% \mathrm{Al}-\mathrm{Zn}$

(b)

FIGURE 3: Photographs and SEM images of the bare metallic coatings after 12 years of exposure.

circuits, optimizing the values of the circuit parameters by using Boukamp' program [32].

All the electrochemical experiments were carried out at laboratory temperature $\left(23 \pm 2^{\circ} \mathrm{C}\right)$ and with the electrochemical cell in a Faraday cage to reduce external interferences as much as possible.

To improve the experimental data reliability, three replicates of each sample type were measured in all the tests.

\section{Experimental Results and Discussion}

\subsection{Atmospheric Exposure Test}

3.1.1. Corrosion of the Metallic Coatings. It is known that all the materials degrade under the influence of atmospheric factors such as oxygen, humidity, and/or pollutants $\left(\mathrm{SO}_{2}\right.$, $\mathrm{NaCl}, \mathrm{NO}_{x}$, etc.). Another important degradation source is the sun radiation, particularly its UV rays. All these influences compose the so-called "Macroclimate" of a determined zone [33]. In change, "Microclimate" is defined as the specific climate formed around an object and it results of vital importance to understand the atmospheric mechanisms causing the materials degradation. Among the parameters used to define it are the surface time of wetness (TOW), the heating by sun radiation, mainly the infrared, and the acidic nature ions $\left(\mathrm{SO}_{3}{ }^{2-}, \mathrm{NO}_{2}{ }^{-}, \mathrm{Cl}^{-}\right)$gathering within the aqueous layer deposited on the object. On the other hand, the atmospheric corrosion process is the sum of partial corrosion processes taking place each time an electrolyte layer deposits on the surface metal. The rain, snow, fog, and/or humidity condensation produced by temperature changes are the main promoters of atmospheric corrosion. In such sense, the value of some climatological variables characterizing the average exposure conditions corresponding to the station used in the present work are shown in Tables 2 and 3. The aggressiveness of La Plata station was attributed to its high relative humidity, severe and lengthy TOW as well as surface runoff supported by the tested replicates.

Hot-dip zinc is widely used as a coating for carbon steel because of its good corrosion resistance and relatively low price [34]. Due to its practical use, zinc atmospheric corrosion has been studied in field exposures as well as in laboratory with controlled environments $[35,36]$. Zincite, $\mathrm{ZnO}$, is the first product formed when the naked metal is 
TABLe 2: Meteorological data for the 12 years of exposure in the CIDEPINT Station, La Plata, Argentina.

\begin{tabular}{|c|c|c|c|c|}
\hline Year & Mean temperature $\left({ }^{\circ} \mathrm{C}\right)$ & Mean relative humidity (\%) & Precipitation $(\mathrm{mm})$ & Days of rain \\
\hline 1 & 16.5 & 80.8 & 943.1 & 90.0 \\
\hline 2 & 16.8 & 80.7 & 1042.8 & 94.0 \\
\hline 3 & 16.3 & 80.4 & 927.0 & 93.0 \\
\hline 4 & 15.8 & 81.8 & 1342.1 & 90.0 \\
\hline 5 & 16.4 & 84.4 & 1316.6 & 98.0 \\
\hline 6 & 16.0 & 82.7 & 1611.8 & 107.0 \\
\hline 7 & 15.8 & 81.1 & 924.5 & 98.0 \\
\hline 8 & 16.1 & 80.8 & 881.7 & 88.0 \\
\hline 9 & 15.9 & 79.4 & 926.6 & 91.0 \\
\hline 10 & 16.0 & 79.0 & 1083.4 & 81.0 \\
\hline 11 & 15.4 & 77.5 & 1153.2 & 85.0 \\
\hline 12 & 16.3 & 78.3 & 775.1 & 70.0 \\
\hline
\end{tabular}

TABLE 3: Average levels of chemical agents, time of wetness and corrosion category of CIDEPINT Station.

\begin{tabular}{|c|c|c|c|c|}
\hline Year & $\begin{array}{c}\text { Deposition rate of } \mathrm{SO}_{2} \\
\left(\mathrm{mg} \cdot \mathrm{m}^{-2} \cdot \mathrm{d}^{-1}\right)\end{array}$ & $\begin{array}{c}\text { Deposition rate of chloride } \\
\left(\mathrm{mg} \cdot \mathrm{m}^{-2} \cdot \mathrm{d}^{-1}\right)\end{array}$ & Time of wetness fraction & $\begin{array}{c}\text { Corrosion category according } \\
\text { to ISO } 9223\end{array}$ \\
\hline 1 & 6.22 & Negligible & 0.61 & $\mathrm{P}_{0} \mathrm{~S}_{0} \tau_{4} / \mathrm{C}_{2}$ \\
\hline 2 & 7.25 & Negligible & 0.62 & $\mathrm{P}_{0} \mathrm{~S}_{0} \tau_{4} / \mathrm{C}_{2}$ \\
\hline 3 & 6.81 & Negligible & 0.61 & $\mathrm{P}_{0} \mathrm{~S}_{0} \tau_{4} / \mathrm{C}_{2}$ \\
\hline 4 & 6.53 & Negligible & 0.65 & $\mathrm{P}_{0} \mathrm{~S}_{0} \tau_{5} / \mathrm{C}_{2}$ \\
\hline 5 & 7.42 & Negligible & 0.63 & $\mathrm{P}_{0} \mathrm{~S}_{0} \tau_{5} / \mathrm{C}_{2}$ \\
\hline 6 & 6.94 & Negligible & 0.69 & $\mathrm{P}_{0} \mathrm{~S}_{0} \tau_{5} / \mathrm{C}_{2}$ \\
\hline 7 & 7.60 & Negligible & 0.59 & $\mathrm{P}_{0} \mathrm{~S}_{0} \tau_{4} / \mathrm{C}_{2}$ \\
\hline 8 & 8.12 & Negligible & 0.57 & $\mathrm{P}_{0} \mathrm{~S}_{0} \tau_{4} / \mathrm{C}_{2}$ \\
\hline 9 & 7.93 & Negligible & 0.61 & $\mathrm{P}_{0} \mathrm{~S}_{0} \tau_{4} / \mathrm{C}_{2}$ \\
\hline 10 & 6.82 & Negligible & 0.62 & $\mathrm{P}_{0} \mathrm{~S}_{0} \tau_{4} / \mathrm{C}_{2}$ \\
\hline 11 & 7.45 & Negligible & 0.62 & $\mathrm{P}_{0} \mathrm{~S}_{0} \tau_{4} / \mathrm{C}_{2}$ \\
\hline 12 & 8.01 & Negligible & 0.55 & $\mathrm{P}_{0} \mathrm{~S}_{0} \tau_{4} / \mathrm{C}_{2}$ \\
\hline
\end{tabular}

exposed to the air, creating a protective film that inhibits corrosion process. Under humidity conditions higher than $80 \%$, zinc is oxidized forming zinc hydroxide. If the $\mathrm{pH}$ on the surface is high enough, this hydroxide can react with atmospheric components such as $\mathrm{CO}_{2}, \mathrm{SO}_{x}$, and $\mathrm{Cl}^{-}$, forming, in the hydroxide/air interface, the corresponding zinc basic salts [37]. Some of these products form a compact film that protects the metal against later corrosive attacks [38]. An important intermediate in the subsequent formation of other corrosion products is hydrozincite $\mathrm{Zn}_{4} \mathrm{CO}_{3}(\mathrm{OH})_{6} \cdot \mathrm{H}_{2} \mathrm{O}[39,40]$. If the $\mathrm{pH}$ of the humid surface is low, neither hydroxide nor basic salts are formed [37]. In presence of $\mathrm{SO}_{2}$ polluted air, the main corrosion product is hydroxysulfate $\mathrm{Zn}_{4} \mathrm{SO}_{4}(\mathrm{OH})_{6} \cdot 4 \mathrm{H}_{2} \mathrm{O}$, and in presence of $\mathrm{Cl}^{-}$ contamination, the precipitation of insoluble hydroxychloride $\mathrm{Zn}_{5}(\mathrm{OH})_{8} \mathrm{Cl}_{2} \cdot \mathrm{H}_{2} \mathrm{O}$ is possible.

The hot-dip aluminium-zinc alloy, known as Zincalume, actually contains about 55\% aluminium, 1.5\% silicon, and the balance zinc. A microstructure of the alloy-coated steel which forms on cooling is essentially two phase, comprising about $80 \%$ by volume of a dendritic aluminium-rich phase and the remainder an interdendritic zinc-rich phase with a thin intermetallic layer next to the steel substrate. When the coating corrodes initially, the zinc phase corrodes preferentially until the formation of corrosion products reduces further activity in these areas. During the initial stage of corrosion, the coating behaves like zinc coating. In the later stages of corrosion when the coating is essentially comprised of zinc corrosion products carried in an aluminium-rich matrix, the corrosion becomes more characteristic of the aluminium-rich phase, resulting in a lower corrosion rate, more typical of aluminium [41, 42].

Weight-loss measurements provide the most reliable figure concerning the aggressiveness of a given atmosphere, so that the corresponding corrosion data approach to the service conditions more than any other test. In the present case, as it is shown in Figure 2 both materials presented a linear relationship between its weight-loss and the weathering time and, considering the 12 years exposure, the galvanized coating exhibited a degree of corrosion 4.94 times greater than that of the $55 \% \mathrm{Al}-\mathrm{Zn}$ coating.

In general, the zinc coating suffered uniform corrosion with the development of a layer of corrosion products, mainly $\mathrm{ZnO}$ and $\mathrm{Zn}_{4} \mathrm{CO}_{3}(\mathrm{OH})_{6} \cdot \mathrm{H}_{2} \mathrm{O}$, but in particular 


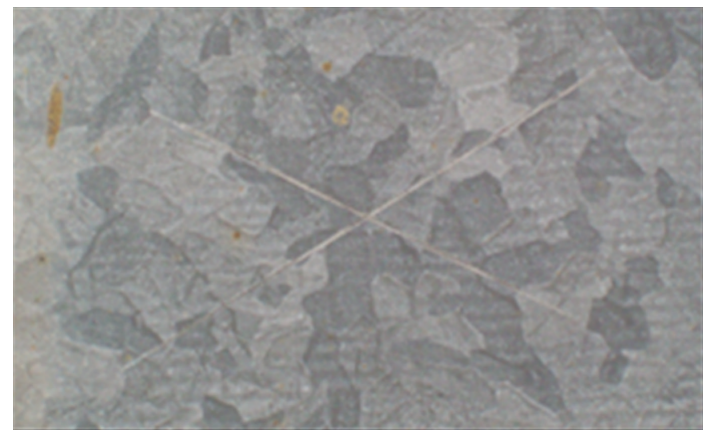

Galvanized steel

(a)

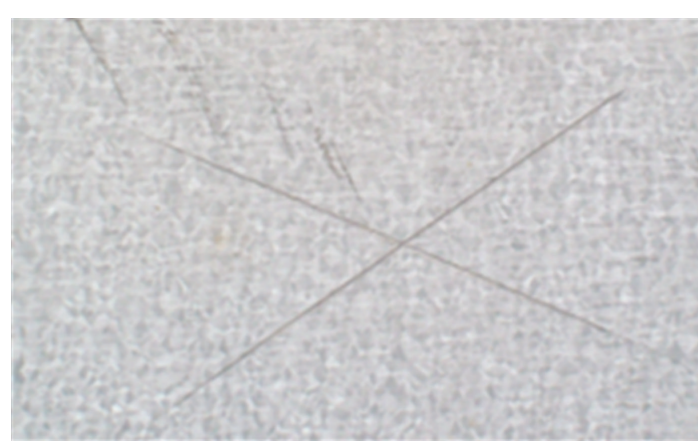

Steel/55\% Al-Zn

(b)

FIgURE 4: Photographs of the scribed area of bare metallic coatings after 12 years of exposure.

places of the surface, the accumulation of atmospheric dust produced localized corrosion as it is possible to see in the SEM images shown in Figure 3. On the other hand, on the $55 \% \mathrm{Al}-\mathrm{Zn}$ coating and due to the complex structure of the alloy, the development of localized corrosion was observed as a consequence of the preferential dissolution of the interdendritic Zn-rich phase, which provoked loss of surface' brightness and the development of thin dark lines related to the aluminium corrosion process.

During all the weathering period, both metallic coatings were able to afford cathodic protection to the substrate as it is shown in Figure 4.

These results can be explained by considering the climatic conditions prevailing during the outdoor exposure prior to samples removal, that is, level of sulphur compounds, wet/dry cycles, high TOW, and pluvial precipitations dissolving the zinc corrosion products and releasing zinc ions from the corroded surface, which are dispersed to the environment. This phenomenon is known today as a metal runoff process [43-50].

3.1.2. Duplex Systems. As a direct way of evaluating the anticorrosive performance of organic coatings, the exposure test to natural atmospheres either for intact or scribed painted surfaces is, without any doubt, the best.

Experimental results coming from exposure tests to natural weather conditions are further representative of the protective and aesthetic properties provided by the topcoat paint. In such a sense, the results obtained from visual inspections periodically carried out for 12 years of exposure in La Plata station confirmed that weathering of the considered duplex systems proceeds very slowly. The periodical visual inspection put in evidence that no sample presented underrusting, peeling, cracking, or checking. From the 4th year weathering and due to the effect of the UV radiation, the Epoxy paint systems showed significant deterioration by chalking, and the topcoat Alkyd paint began to show significant changes of color, brightness, and chalking that led to the exposure of the primer from the 8th year of test. In any case, blistering or filiform corrosion near the scribed cross was observed. Examples of this behavior are presented on Figures 5 and 6 . These results were attributed to the highest resistance of the polyurethane topcoat paint to the UV radiation, rain and temperature changes due to the strong interaction between the reactive components of the polymer and the chemically stable pigment $\left(\mathrm{TiO}_{2}\right)$ added to the effective anticorrosive protection offered by the primer.

At this point, it is noteworthy to remark that besides knowing the behavior of painting systems when they are intact, it is important to evaluate how they performed when mechanical damage occurs. For that purpose, some of the samples were scribed in an $\mathrm{X}$-shape before being exposed to the natural atmosphere.

The main characteristic of duplex systems is to get and maintain good adhesion to the metallic-coated steel surface during its weathering period. As it is shown in Figure 7, independent of the metallic substrate the polyurethane coating presented the largest adhesion loss during the weathering. Due to the previously mentioned behavior of Epoxy and Alkyd paint systems from the 4th year of weathering, is important to mention that in the case of both Alkyd systems the adhesion test considered mainly the primer and in the case of the Epoxy-based samples the evaluation was interrupted as a consequence of the observed chalking degree.

3.2. Electrochemical Tests. During atmospheric corrosion, in general, the metal is not immersed in large quantities of electrolyte but in contact with thin layers or monolayers of moisture, due to that the corrosion process develops as localized corrosion cells. In that situation, the measurement of the corrosion potential as well as of the resistive and capacitive parameters governing the electrochemical behavior of the metal/coating interface is not always possible during the atmospheric corrosion $[51,52]$.

According to Zhang and Lyon [52], the cathodic process for metals like steel, zinc, and copper coated with thin $(<100 \mu \mathrm{m})$ water films reveals a diffusional limiting current whose value depends on the water film thickness. For thinner thicknesses, like in most of the atmospheric corrosion cases, the main cathodic process is controlled by activation. In the case of zinc, due to its high electronegativity, the cathodic process is not sensitive to the water film thickness present on 
Z9

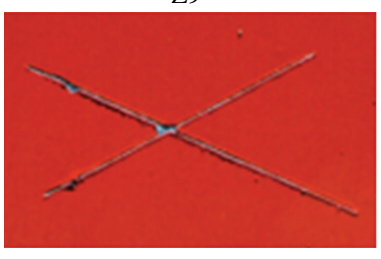

$t=0$

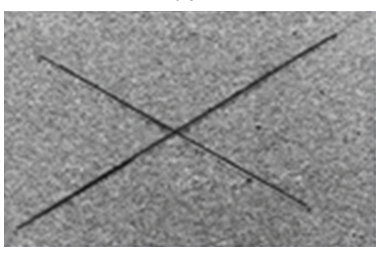

$t=0$

Z114

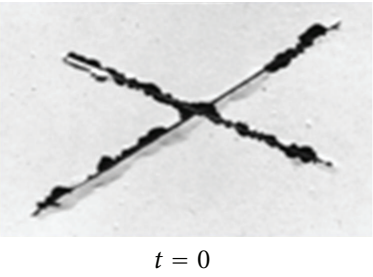

Z9

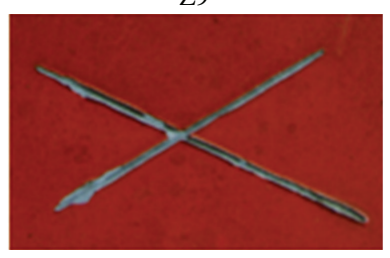

$t=804$ days

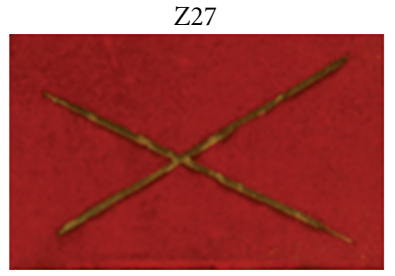

$t=4$ years

S/Z/AS system
Z73

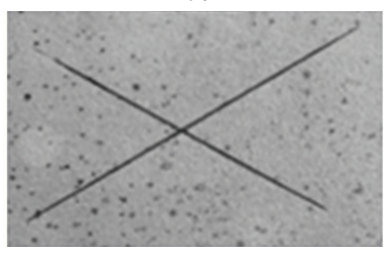

$t=804$ days
Z73

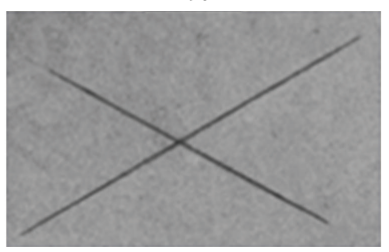

$t=4$ years

S/Z/ES system
Z109

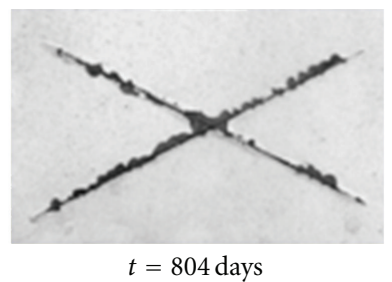

Z114

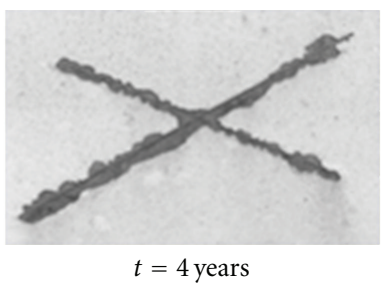

Z27

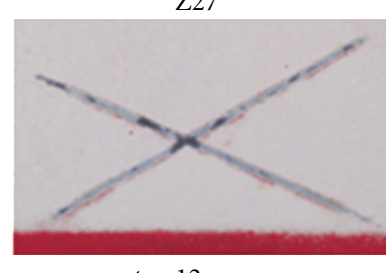

$t=12$ years 
A30

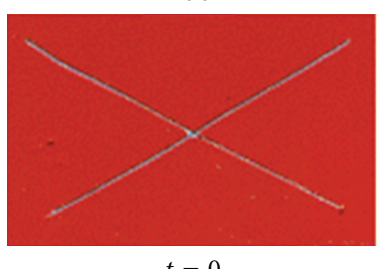

$t=0$

A72

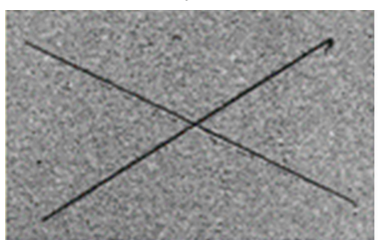

$t=0$

A112

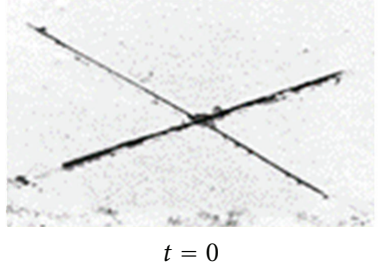

A31

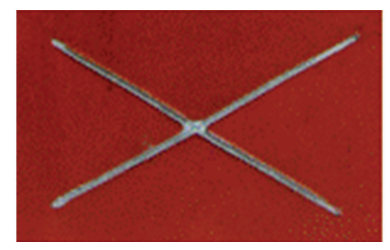

$t=804$ days
A31

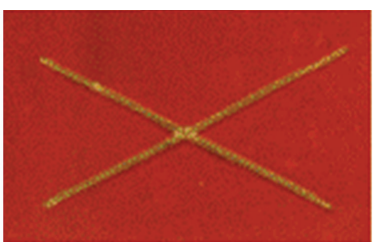

$t=4$ years

S/ZA/AS system

A73

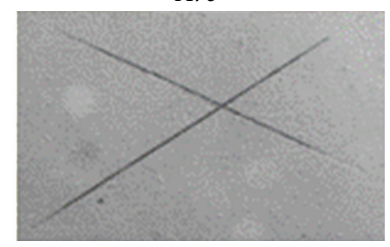

$t=804$ days
A72

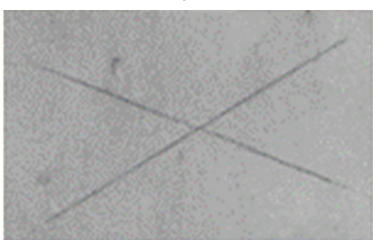

$t=4$ years
A30

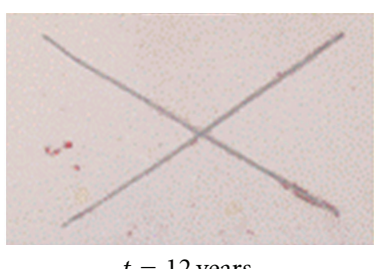

$t=12$ years

S/ZA/ES system

A114

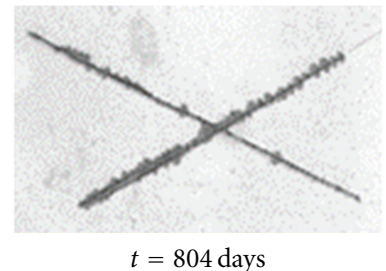

A115

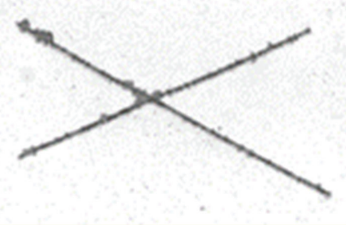

$t=4$ years
A73

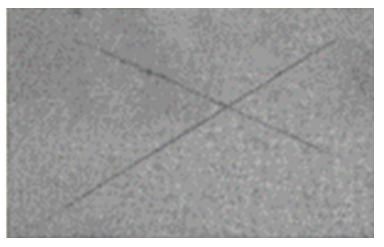

$t=12$ years

S/ZA/PS system

FIGURE 6: Photographs showing the evolution of S/ZA/painting systems as a function of the exposure time.

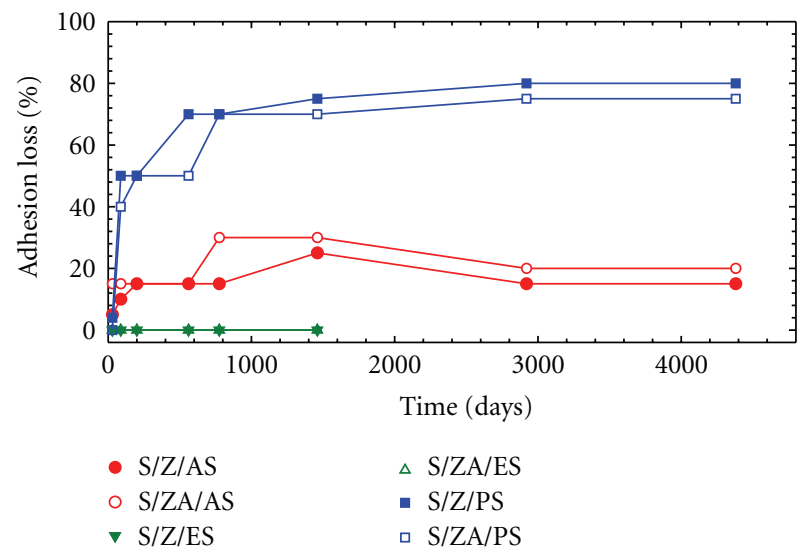

FIgURE 7: Plots showing the time dependence of the adhesion loss suffered by the painted S/Z and S/ZA sheets.

structure that is usually formed on the surface. The first time constant $\left(R_{1} C_{1}\right)$ may be linked with the compact inner layer of $\mathrm{ZnO}$ and the second one $\left(R_{2} C_{2}\right)$ with the external and porous layer of $\mathrm{Zn}_{4} \mathrm{CO}_{3}(\mathrm{OH})_{6} \cdot \mathrm{H}_{2} \mathrm{O}[55,56]$. This surface film seems to inhibit further metal dissolution, although the environmental conditions determine the extent of corrosion progress due to a competition between film formation and film removal reactions. It was found that data of zinc corrosion measurements correlate with the air pollution levels given as a function of the $\mathrm{SO}_{2}$ and $\mathrm{Cl}^{-}$ concentrations [57].

For similar exposure conditions, the influence of the coating composition on the bare sheet impedance values is shown in Figure 10. In it can be seen that the charge transfer 


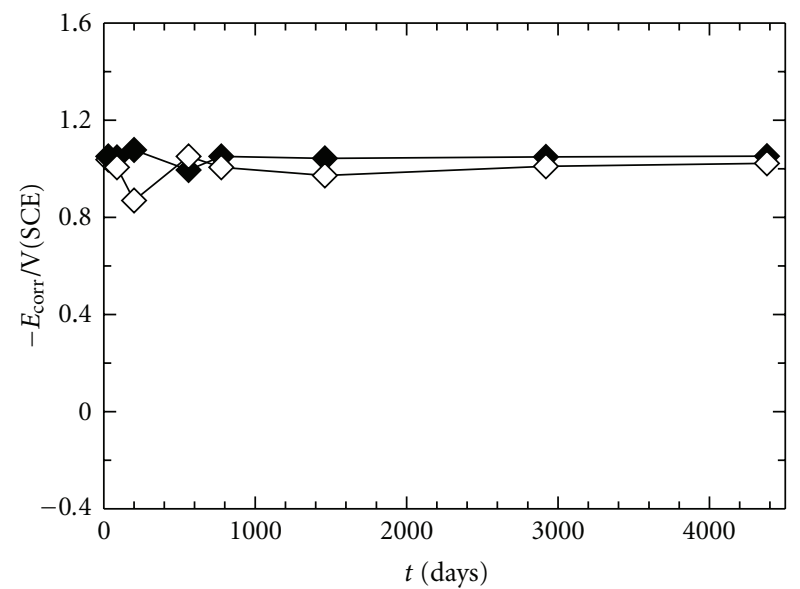

$\diamond \mathrm{S} / \mathrm{Z}$

$\diamond S / Z A$

FIgURE 8: Plots showing the time dependence of the $E_{\text {corr }}$ values of bare $S / Z$ and S/ZA sheets as a function of the exposure time.

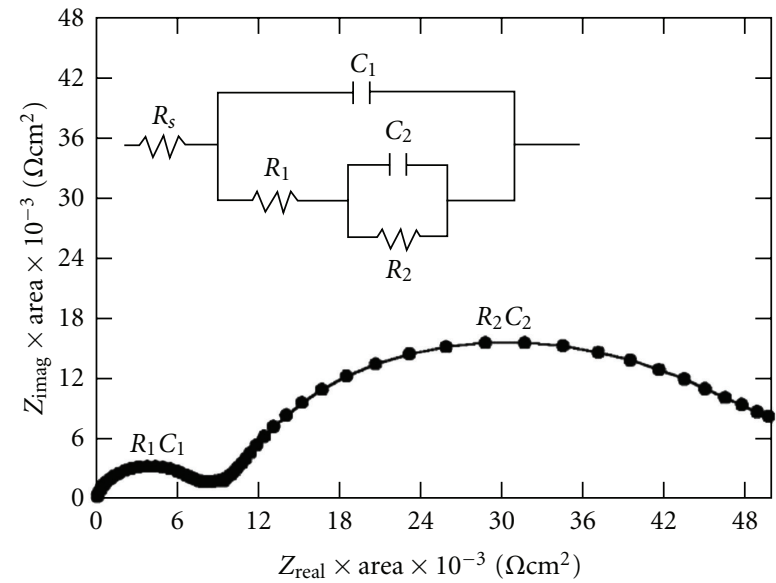

Figure 9: Equivalent circuit model used for fitting the tested bare S/Z and S/ZA sheets.

resistance $\left(R_{1}\right)$ values shown by the $55 \% \mathrm{Al}-\mathrm{Zn}$ alloy was slightly higher than that of the zinc layer but the resistive contribution $\left(R_{2}\right)$ of the external and porous layer to the system total impedance was very similar. These results are in accordance with the electrochemical activation demonstrated by both metallic surfaces.

\subsubsection{Corrosion Potential and Impedance Results for Painted} $S / Z$ and $S / Z A$ Sheets. Rest or corrosion potential ( $\left.E_{\text {corr }}\right)$ measurements for painted metals and their time dependence have been questioned with regard to their use as a technique for evaluating the anticorrosive resistance of organic coatings [58]. However, its changes as a function of the exposure time to aqueous media have been successfully used as a simple tool to study the corrosion protection afforded by organic coatings [59-62]. Depending upon the microstructure of the paint coating, especially its polymerization degree, a certain period elapses until electrolyte penetration channels are established through which the underlying metal comes into contact with the medium. So, it is not surprising that, when a compact structure and high crosslinking level are accompanied by an also high film thickness, a few days of testing is not enough time for the electrolyte to enter in contact with the base metal of coated specimens, form the electrochemical double layer, and enable the measurement of a corrosion potential.

Figure 11 shows the corrosion potential $\left(E_{\text {corr }}\right)$ values measured for each coated steel sheet exposed to the natural atmosphere of La Plata station. As can be seen, the $E_{\text {corr }}$ values measured almost from the beginning and up to the end of the test for S/Z/AS, S/ZA/AS, S/Z/ES, and S/ZA/ES were quite similar to those obtained for the bare $S / Z$ and $\mathrm{S} / \mathrm{ZA}$ sheets (between -0.9 and $-1.1 \mathrm{~V} / \mathrm{SCE}$ ). This means that, at least from the thermodynamic point of view, the protective properties offered by the alkyd- and epoxy-based painting systems were not sufficiently effective as to avoid the onset of the underlying zinc or 55\% Al-Zn corrosion. On the other hand, the polyurethane-based painting system offered 


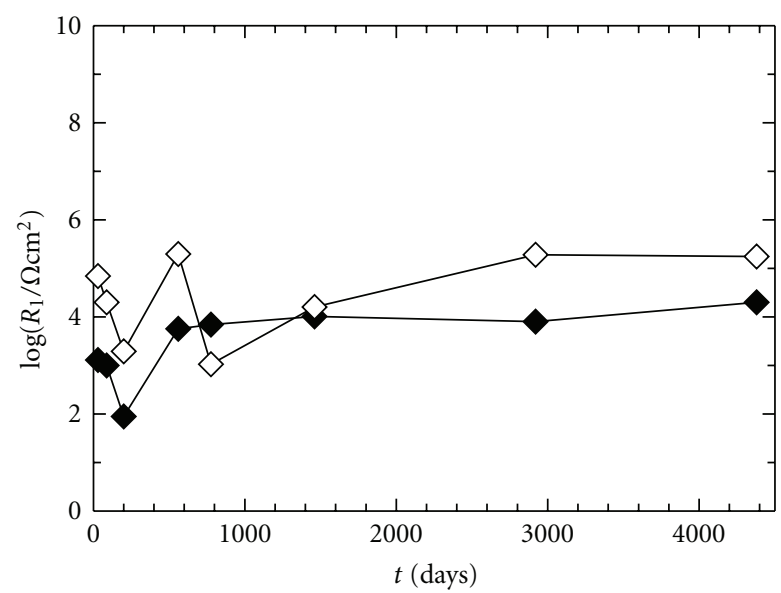

(a)

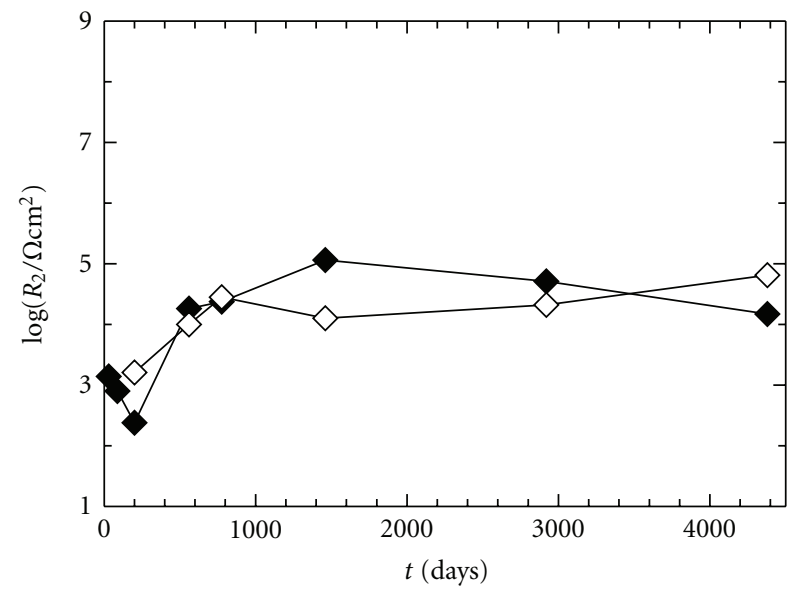

$\bullet \mathrm{S} / \mathrm{Z}$

$\diamond S / Z A$

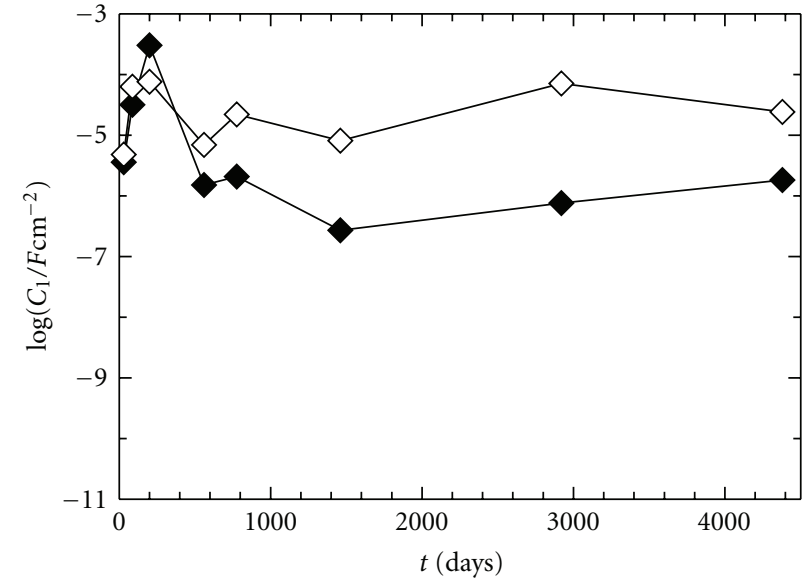

(b)

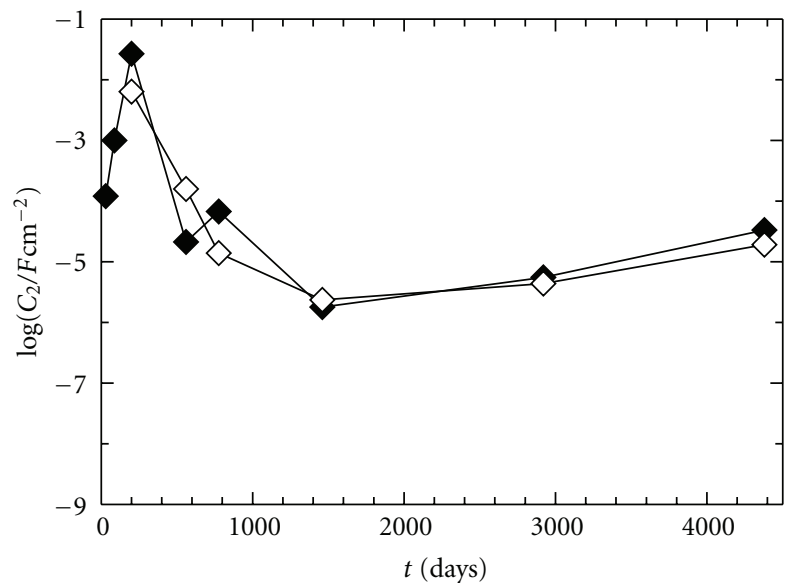

$\diamond \mathrm{S} / \mathrm{Z}$

$\diamond S / Z A$

(c)

(d)

FIGURE 10: Evolution of $\log R_{1}, \log C_{1}, \log R_{2}$, and $\log C_{2}$ parameters of the tested bare S/Z and S/ZA sheets.

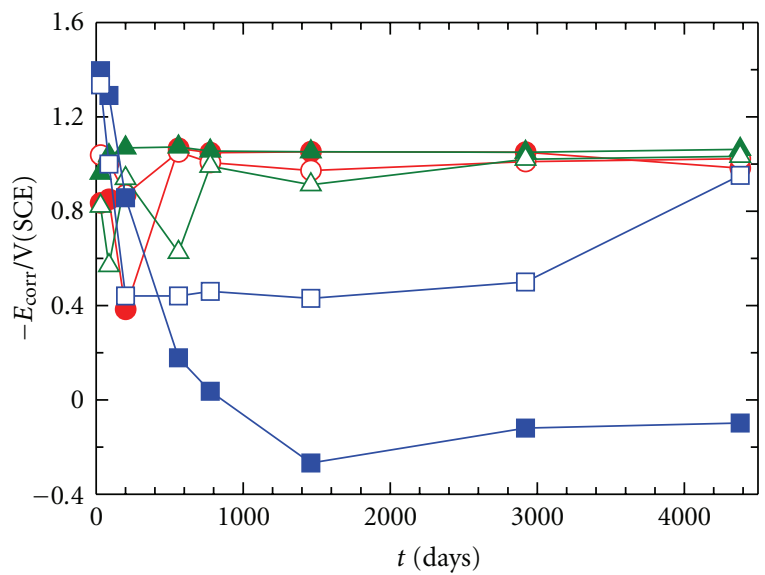
S/Z/AS
$\triangle \mathrm{S} / \mathrm{ZA} / \mathrm{ES}$
S/ZA/AS
S/Z/PS
A S/Z/ES
$\square$ S/ZA/PS

FIGURE 11: Plots showing the time dependence of the $E_{\text {corr }}$ values of painted S/Z and S/ZA sheets as a function of the exposure time. 
much more promising protective properties, particularly when applied on S/Z sheets, since the S/Z/PS system potential values remained in an electrochemically passive zone. A similar performance was supplied by the S/ZA/PS up to almost reaching the 12 years of exposure where together with the measurement of an $E_{\text {corr }} \approx-1.00 \mathrm{~V} / \mathrm{SCE}$, the first sign of a localized corrosion was detected by EIS.

Since the main difference among the S/Z/painting systems and S/ZA/painting systems was the applied paint formulation used in each case, it is assumed that the magnitude of the $E_{\text {corr }}$ displacements may be particularly associated with both the relative easiness with which the climatic variables affect the paint film structure and, hence, its protective properties. However, and it will be discussed in the next paragraph, except in the case of the epoxy-based painting system, the other two were able to protect relatively (AS) and effectively (PS) the metallic substrate from the corrosive atmosphere. This conclusion arises from the fact that the corrosion potential values measured for the S/Z/PS and S/ZA/PS panels were mostly nobler than the corresponding to bare $\mathrm{S} / \mathrm{Z}$ or S/ZA sheets subjected to the same experimental conditions. This effective protection was mainly attributed to the PS barrier painting system, which could resist the strong aggressive action coming from the atmospheric conditions.

The impedance modulus $(|Z|)$ of replicated samples as a function of their exposure time to the natural atmosphere of La Plata station illustrates Figure 12. A fast and simple qualitative analysis of this figure allows to infer that both the shape of all the experimental diagrams was fairly similar and it is possible to presume the presence of at least two time constants, one at low frequencies and another at high frequencies.

As seen in Figure 12, all the tested systems showed changes more or less significant of their $(|Z|)$ and phase angle (Theta) during the weathering period. The fluctuating impedance values can be attributed to the dynamic behavior of the painting system structure frequently subjected to wet/dry cycles and/or other climatic changes as well as of the metal/paint interface through which the corrosion products gathered at the bottom and/or within the coating defects enhanced the coating barrier protection and, therefore, contribute to an increase in the impedance of the protective system at medium and low frequencies; however, as the time elapses, new defects appear at the weaker (less protective areas) paint layer allowing the inducing corrosion species permeation, and, consequently, the development of new electrochemically active zones.

The fact that the initial substrate attack is localized could be ascribed to the presence of very small defects in the paint layer, which act as an electrical shunt. As the exposure time goes on, the equilibrium between the development rate of the corrosion products and their diffusion rate towards the outdoor medium may be reached and, consequently, the total impedance fluctuations become small.

(1) Equivalent Circuit Models. The painting system as well as the $\mathrm{S} / \mathrm{Z}$ or $\mathrm{S} / \mathrm{ZA}$ substrates deterioration takes place from processes having a complex nature. Consequently, to interpret and explain in electrochemical terms the time dependence of the acquired impedance data, it has been necessary to propose appropriate equivalent circuit models.

Impedance spectra provide useful information concerning the evolution of both the protective features of the organic coating and the kinetics of the underlying metallic substrate corrosion process as a function of the exposure time to experimental or real service conditions. Thus, the dynamic character of the painting system barrier properties, the anticorrosive action of specific pigments, the corrosion products formation, and also changes in the disbonded area are accounted for the time dependence of the coated steel/medium impedance spectra. In general, an explanation of why and how such changes take place can be given by associating them to the resistive and capacitive parameters derived from fitting impedance data with nonlinear least squares algorithms involving the transfer function of the equivalent circuit model shown in Figure 13, [63-67]. They represent the parallel and/or series connection of some resistors and capacitors, simulating a heterogeneous arrangement of electrolytically conducting paths, where $R$ represents the electrolyte resistance between the reference and working (coated steel) electrodes, $R_{c}$ (resistance to the ionic flux) describes paths (pores, low crosslinking) of lower resistance to the electrolyte diffusion short-circuiting the paint film, and $C_{c}$ is the dielectric capacitance representing the intact part of the same paint film [68]. Once the permeating and corrosion-inducing chemicals (water, oxygen and ionic species) reach electrochemically active areas of the substrate, particularly at the bottom of the paint film defects, the metallic corrosion become to be measurable so that its associated parameters, the electrochemical double-layer capacitance, $C_{\mathrm{dl}}$, and the charge transfer resistance, $R_{t}$, can be estimated. It is important to remark that the values of these parameters vary direct $\left(C_{\mathrm{dl}}\right)$ and inversely $\left(R_{t}\right)$ with the size of the corroding area.

On the other hand, distortions observed in these resistive-capacitive contributions indicate a deviation from the theoretical models in terms of a time constants distribution due to either lateral penetration of the electrolyte at the steel/paint interface (usually started at the base of intrinsic or artificial coating defects), underlying metallic substrate surface heterogeneity (topological, chemical composition, surface energy), and/or diffusion processes that could take place along the test $[69,70]$. Since all these factors make the impedance/frequency relationship nonlinear, they are taken into consideration by replacing one or more capacitive components $\left(C_{i}\right)$ of the equivalent circuit transfer function by the corresponding constant phase element $Q_{i}(\mathrm{CPE})$, whose impedance dispersion relation is given by $Z=$ $(j \omega)^{-n} / Y_{0}$ and $n=$ CPE power $=\alpha /(\pi / 2)[32,71]$.

Difficulties in providing an accurate physical description of the occurred processes are sometimes found. In such cases, a standard deviation value $\left(\chi^{2}<5 \times 10^{-4}\right)$ between experimental and fitted impedance data may be used as final criterion to define the most probable circuit.

According to the impedance data dispersion, the fitting process was performed using either the dielectric capacitance $C_{i}$ or the phase constant element $Q_{i}$; however, the $C_{i}$ 

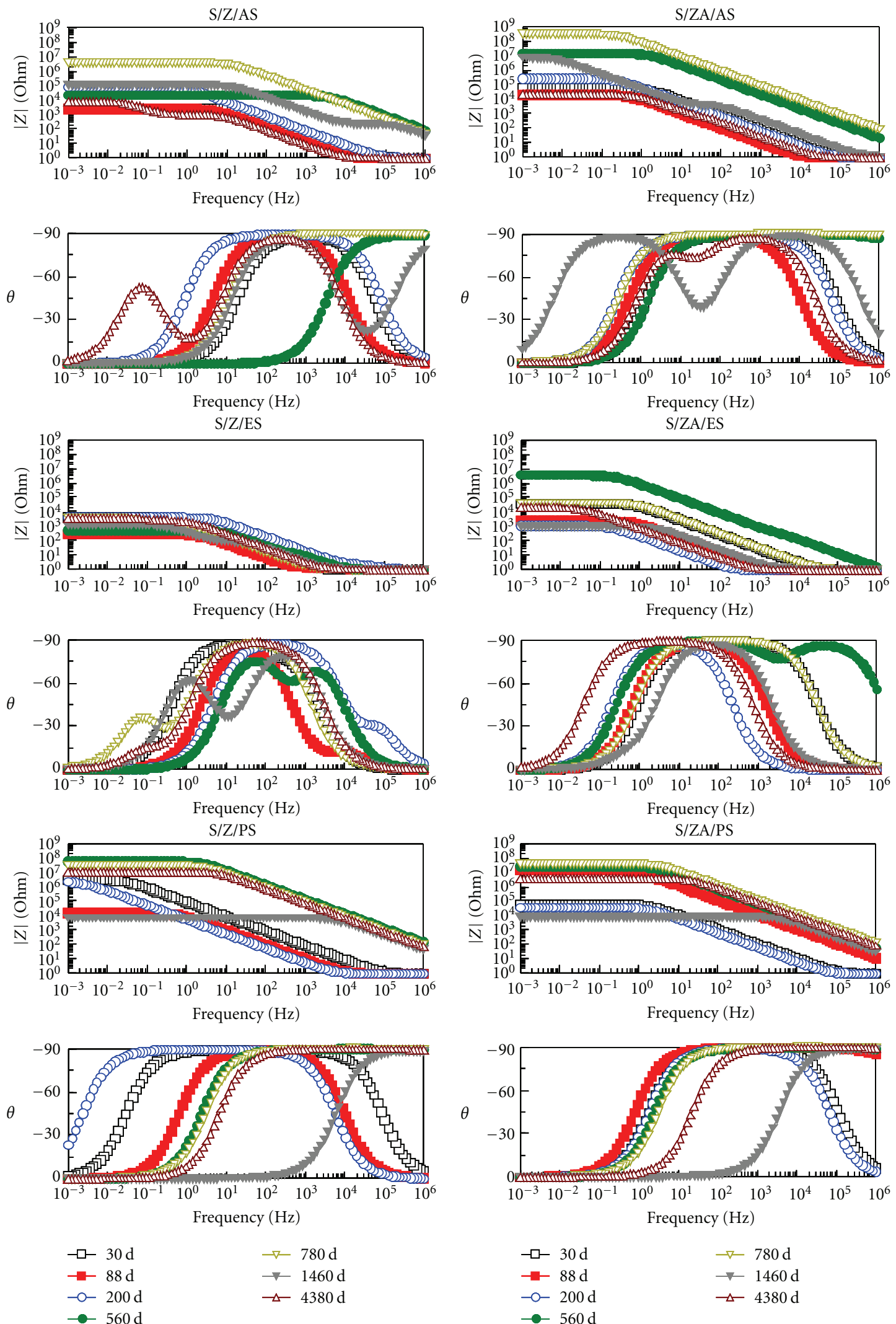

$$
\begin{array}{ll}
\rightarrow-30 \mathrm{~d} & \rightarrow-780 \mathrm{~d} \\
-88 \mathrm{~d} & \rightarrow-1460 \mathrm{~d} \\
-0-200 \mathrm{~d} & \rightarrow-4380 \mathrm{~d} \\
\rightarrow-560 \mathrm{~d} &
\end{array}
$$

FIGURE 12: Bode plots showing the time dependence of the duplex systems impedance during their exposure to the natural atmosphere of La Plata station for 12 years. 


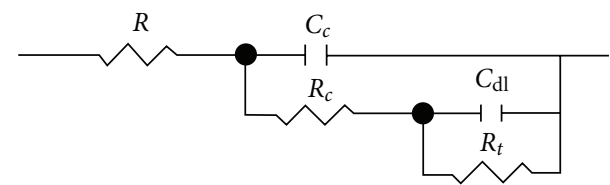

Figure 13: Equivalent circuit model used for fitting the tested duplex systems.

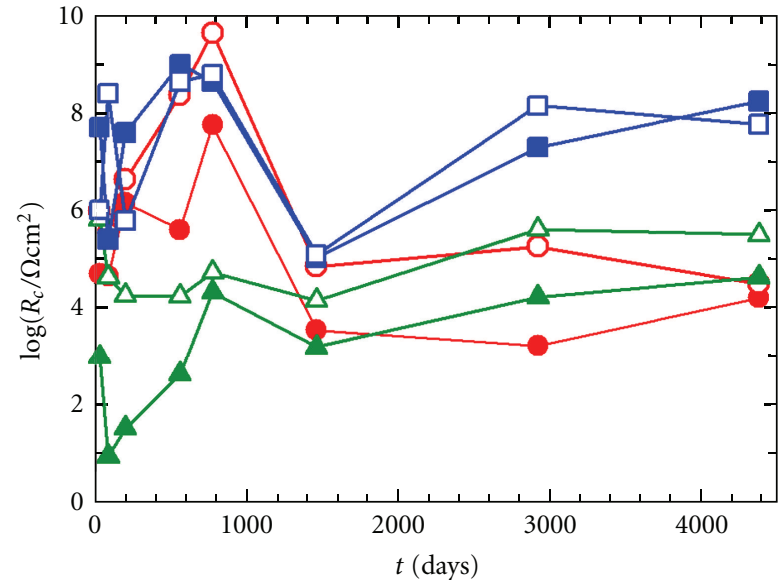

(a)

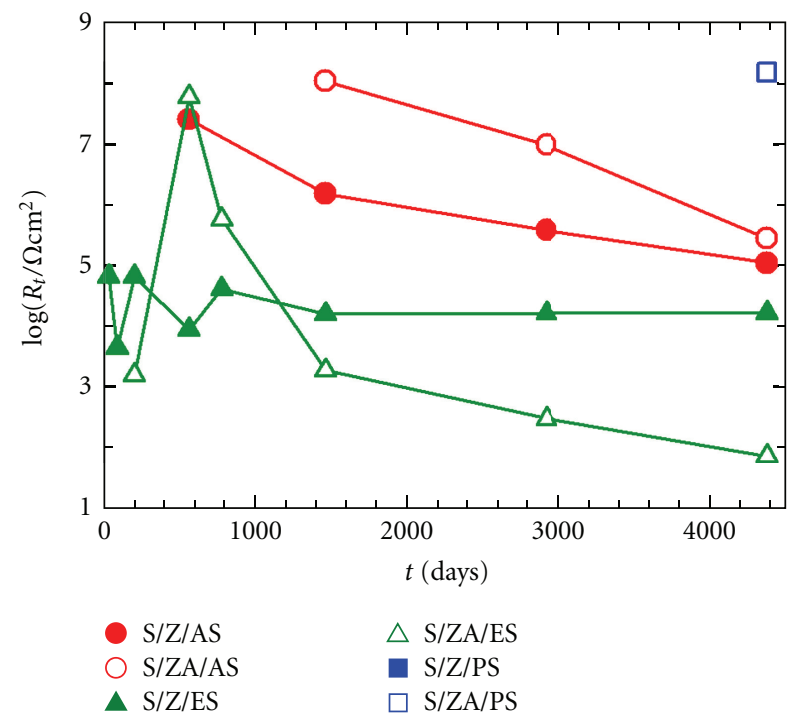

(c)

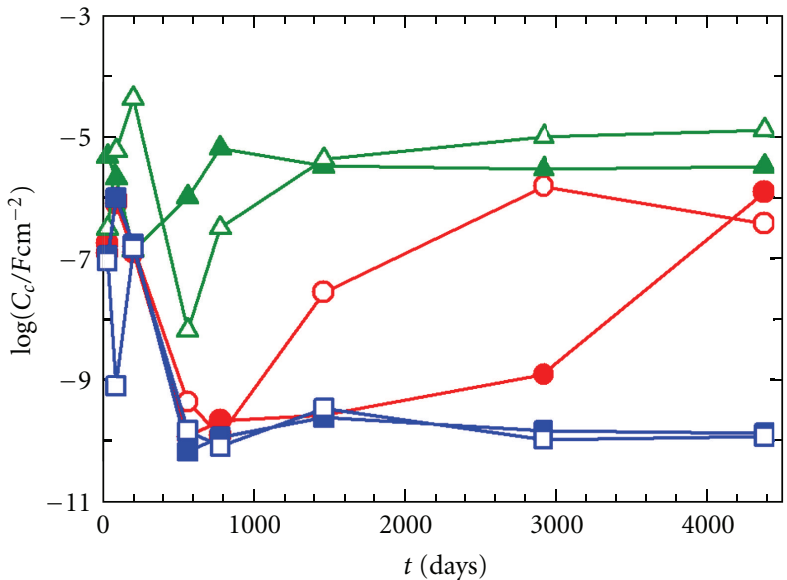

(b)

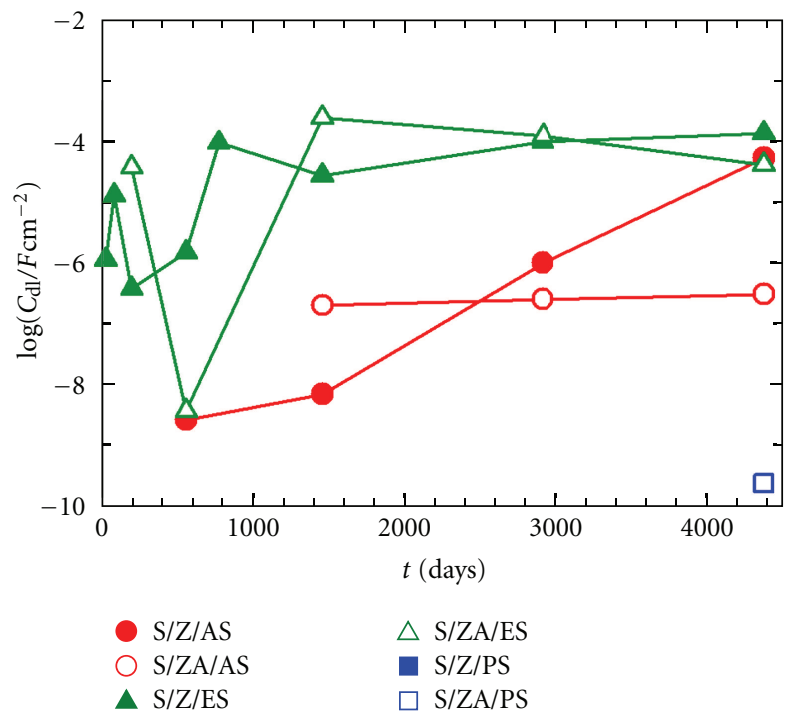

(d)

Figure 14: Evolution of $R_{c}, C_{c}, R_{t}$, and $C_{\mathrm{dl}}$ parameters of the duplex systems impedance during their exposure to the natural atmosphere of La Plata station for 12 years.

parameter was used in the following plots to facilitate the results visualization and interpretation.

(2) Time Dependence of the Impedance Resistive and Capacitive Components. The values of the resistive and capacitive components of the impedance corresponding to all the painted samples exposed to the natural atmosphere of La Plata station for 12 years are shown in Figure 14. As seen, the S/Z/PS and S/ZA/PS samples offered an excellent anticorrosive performance up to the end of the exposure.
This behavior could be attributed to its excellent barrier effect due to the structurally homogeneous and strong paint film $\left(R_{c} \approx 10^{7}-10^{8} \Omega \mathrm{cm}^{2}, C_{c} \approx 10^{-10}-10^{-9} \mathrm{Fcm}^{-2}\right)$, which was able to counteract the significant adhesion loss suffered by this painting system during weathering and slowed down the development of the alloy coating corrosion process up to the end of the exposure.

For the other two sample types, a rather highly fluctuating $R_{c}$ values (two or more orders of magnitude) were found within the first 1400 days of exposure but then, and 
up to the end of the test, they remained changing between $10^{6}-10^{4} \Omega \mathrm{cm}^{2}$; on the other hand, its coupled dielectric capacitance $\left(C_{c}\right)$ followed the same unstable trend at the beginning of the test but then, due to the deterioration degree reached by the AS and ES painting systems as a consequence of the adverse climatic conditions, led to $C_{c}$ values $\left(\approx 10^{-6}-10^{-5} \mathrm{Fcm}^{-2}\right)$, that is, close to the bare $S / Z$ and S/ZA sheets.

On the other hand, the same Figure shows great differences in the electrochemical response $\left(R_{t} C_{\mathrm{dl}}\right)$ of the different systems. In the case of the polyurethane systems, the corrosion process was either absent (S/Z/PS) or at least its development was delayed up to the end of exposure (S/ZA/PS). On the contrary, for the rest of the considered duplex systems after variable induction periods, the metallic coating degradation was detected. The worst corrosion protection was afforded by the Epoxy-based painting system since the corrosion process was detected by EIS at 30 (S/Z/ES) and 200 (S/ZA/ES) days. This behavior would be ascribed to the different electrochemical reactivity of the $\mathrm{Z}$ and $\mathrm{ZA}$ coatings. In the case of the Alkyd system, the induction period was of 600 and 1400 days for S/Z/As and S/ZA/AS, respectively. Again, the better performance of the last system could be accredited to a relatively good, although too short for practice purposes, barrier effect offered by the paint film added to the lower electrochemical reactivity of the S/ZA sheet.

\section{Conclusions}

At the end of this work, it is possible to summarize some conclusions valid for the studied materials.

All the laboratory and field tests involved in this work were useful to understand the behavior of the studied duplex systems subjected to natural weathering at La Plata Station. The good correlation between visual inspection and electrochemical tests allowed explaining some troubles observed in practice and, on this base, contribute to solve them to maintain its useful life as long as possible.

An almost constant corrosion rate of bare zinc and zincaluminum layers acting as galvanic coating of steel sheets was found during the long-term exposure to the natural atmosphere of the La Plata station. Both materials were able to cathodically protect the steel substrate for 12 years.

Regarding the comparative study among the three painting systems applied on $\mathrm{S} / \mathrm{Z}$ or $\mathrm{S} / \mathrm{ZA}$ sheets, different $R_{c} C_{c}$ and $R_{t} C_{\mathrm{dl}}$ evolutions were obtained depending mainly on the paint. The best protective performance offered by the Polyurethane-based painting system was explained in principle taking in account its better barrier properties. The experimental results coming from the alkyd- and epoxybased painting systems were not satisfactory due to their low resistance to the atmospheric conditions existing at La Plata station.

Despite the interface degradation (loss of adhesion) shown by all the painting systems, the corrosion process did not progress from the cross cut towards the underlying metallic substrate.

\section{Acknowledgments}

The authors thank the Comisión de Investigaciones Científicas de la Provincia de Buenos Aires (CICPBA), the Consejo Nacional de Investigaciones Científicas y Técnicas (CONICET), and the Universidad Nacional de La Plata for the financial support to carry out the present paper.

\section{References}

[1] M. Stratmann, K. Bohnenkamp, and W. J. Engell, "An electrochemical study of phase-transitions in rust layers," Corrosion Science, vol. 23, no. 9, pp. 969-985, 1983.

[2] L. Ferretti, E. Traverso, and G. Ventura, "Marine corrosion of mild steel in a thermically altered natural environment," AntiCorrosion Methods and Materials, vol. 23, no. 5, pp. 3-5, 1976.

[3] C. E. Bird and F. J. Strauss, "Effect of wet storage staining on subsequent atmospheric corrosion of galvanized iron sheets," Materials Performance, vol. 15, no. 11, p. 27, 1976.

[4] F. E. Goodwin, "Mechanism of corrosion of Zinc and Zinc -5\% Aluminum steel sheet coatings," in Zinc-Based Steel Coatings Systems: Metallurgy and Performance, G. Krauss, Ed., pp. 183193, The Minerals, Metals \& Materials Society, Warrendale, Pa, USA, 1990.

[5] M. Pourbaix, "Une méthode éléctrochimique rapide de predetermination de la corrosion atmospherique," Tech. Rep. 1, CEBELCOR, 1969.

[6] Y. Suzuki, Y. Hisamatsu, and N. Masuko, "Nature of atmospheric rust on iron," Journal of the Electrochemical Society, vol. 127, no. 10, pp. 2210-2214, 1980.

[7] ASM Handbook, vol. 13 of Corrosion: Materials, ASM International, 1992.

[8] J. C. Zoccola, H. E. Townsend, A. R. Borzillo, and J. B. Horton, "Atmospheric factors affecting the corrosion of engineering metals," in Proceedings of the American Society for Testing and Materials (STP '78), vol. 646, pp. 165-184, 1978.

[9] F. C. Porter, Zinc Handbook: Properties, Processing and Use in Design, Marcel Dekker, New York, NY, USA, 1991.

[10] J. F. H. van Eijnsbergen, Duplex Systems, vol. 7, Elsevier, Amsterdam, The Netherlands, 1994.

[11] K. L. Mittal, "Stresses and adhesion of thin metallic coatings on oxide substrates," in Adhesion Measurements of Film and Coatings, K. L. Mittal, Ed., pp. 1-13, VSP, Utrecht, The Netherlands, 1995.

[12] Steel Structure Painting Manual. Systems and Specifications, vol. 2, Steel Structures Painting Council, Pittsburgh, Pa, USA, 7th edition, 1995.

[13] J. F. Malone, "Painting hot dip galvanized steel," Materials Performance, vol. 31, no. 5, pp. 39-42, 1992.

[14] C. H. Hare, "Corrosion and the preparation of metals for painting," in Unit 26 Federation Series on Coatings Technology, Federation of Societies for Coatings Technology, Philadelphia, $\mathrm{Pa}$, USA, 1978.

[15] K. W. Allen, Strength and Structures. Aspect of Adhesion, vol. 1, University Press of London, London, UK, 1965.

[16] T. R. Bullet and A. T. S. Rudram, "The coating and the substrate," Journal of the Oil and Colour Chemists' Association, vol. 44, pp. 787-807, 1961.

[17] C. H. Hare, Good Painting Practice. Steel Structure Painting Manual, Steel Structures Painting Council, Pittsburgh, Pa, USA, 3rd edition, 1995.

[18] R. Barnhart, D. Mericle, Ch. Mobley, T. Hocking, J. H. Bogran, and E. McDaniel, "Why surface preparation is important?" 
Journal of Protective Coatings and Linings, vol. 14, no. 9, pp. 61-64, 1997.

[19] H. Leidheiser Jr., "Corrosion of painted metals-a review," Corrosion, vol. 38, no. 7, pp. 374-383, 1982.

[20] I. Sekine, M. Yuasa, N. Hirose, and T. Tanaki, "Degradation evaluation of corrosion protective coatings by electrochemical, physicochemical and physical measurements," Progress in Organic Coatings, vol. 45, no. 1, pp. 1-13, 2002.

[21] G. Rocchini, "The importance of choosing the correct electrochemical technique for evaluating corrosion rates," Corrosion Prevention and Control, vol. 48, no. 4, pp. 125-134, 2001.

[22] S. Maeda, "Surface chemistry of galvanized steel sheets relevant to adhesion performance," Progress in Organic Coatings, vol. 28, no. 4, pp. 227-238, 1996.

[23] R. L. Howard, I. M. Zin, J. D. Scantlebury, and S. B. Lyon, "Inhibition of cut edge corrosion of coil-coated architectural cladding," Progress in Organic Coatings, vol. 37, no. 1, pp. 8390, 1999.

[24] R. L. Howard, S. B. Lyon, and J. D. Scantlebury, "Accelerated tests for the prediction of cut-edge corrosion of coil-coated architectural cladding. Part I: cyclic cabinet salt spray," Progress in Organic Coatings, vol. 37, no. 1, pp. 91-98, 1999.

[25] R. L. Howard, S. B. Lyon, and J. D. Scantlebury, "Accelerated tests for prediction of cut edge corrosion of coil-coated architectural cladding. Part II: cyclic immersion," Progress in Organic Coatings, vol. 37, no. 1, pp. 99-105, 1999.

[26] S. Feliu, V. Barranco, and S. Feliu, "Contradictory results of the UVCON and saline immersion tests regarding the evaluation of some inhibitor/lacquer combinations on galvanised coatings," Progress in Organic Coatings, vol. 50, no. 3, pp. 199-206, 2004.

[27] A. R. di Sarli and R. A. Armas, "An assessment of the anticorrosive properties of epoxy paints. Correlation between impedance measurements and the salt-spray cabinet test," Corrosion Prevention \& Control, vol. 36, no. 5, pp. 127-131, 1989.

[28] P. R. Seré, J. D. Culcasi, C. I. Elsner, and A. R. Di Sarli, "Study of the corrosion process at the galvanized steel/organic coating interface," in Proceedings of the SCANNING '98, vol. 20, no. 3, pp. 274-275, Baltimore, Md, USA, 1998.

[29] B. M. Rosales, A. R. di Sarli, F. Fragata et al., "PATINA network-performance of coil coating in natural atmospheres of Ibero-America," Revista de Metalurgia, vol. Extra, pp. 201205, 2003.

[30] B. M. Rosales, A. R. di Sarli, O. de Rincón, A. Rincón, C. I. Elsner, and B. Marchisio, "An evaluation of coil coating formulations in marine environments," Progress in Organic Coatings, vol. 50, no. 2, pp. 105-114, 2004.

[31] B. Del Amo, L. Véleva, C. I. Elsner, and A. R. di Sarli, "Performance of coated steel systems exposed to different media: part I. Painted galvanized steel," Progress in Organic Coatings, vol. 50, no. 3, pp. 179-192, 2004.

[32] B. A. Boukamp, Report CT88/265/128, CT89/214/128, University of Twente, Amsterdam, The Netherlands, 1989.

[33] E. V. Schmid, Exterior Durability of Organic Coatings, FMJ International Publications, Redhill, UK, 1988.

[34] S. C. Chung, A. S. Lin, J. R. Chang, and H. C. Shih, "EXAFS study of atmospheric corrosion products on zinc at the initial stage," Corrosion Science, vol. 42, no. 9, pp. 1599-1610, 2000.

[35] Q. Qu, C. Yan, Y. Wan, and C. Cao, "Effects of $\mathrm{NaCl}$ and $\mathrm{SO}_{2}$ on the initial atmospheric corrosion of zinc," Corrosion Science, vol. 44, no. 12, pp. 2789-2803, 2002.

[36] J. Morales, S. Martín-Krijer, F. Díaz, J. Hernández-Borges, and S. González, "Atmospheric corrosion in subtropical areas: influences of time of wetness and deficiency of the ISO 9223 norm," Corrosion Science, vol. 47, no. 8, pp. 2005-2019, 2005.

[37] V. Kucera and E. Mattsson, Corrosion Mechanisms, Marcel Dekker, New York, NY, USA, 1987.

[38] T. E. Graedel, "Corrosion mechanisms for zinc exposed to the atmosphere," Journal of the Electrochemical Society, vol. 136, no. 4, pp. 193C-203C, 1989.

[39] X. G. Zhang, Corrosion and Electrochemistry of Zinc, Plenum Press, New York, NY, USA, 1996.

[40] F. Mansfeld, Corrosion Mechanisms, Marcel Dekker, New York, NY, USA, 1987.

[41] H. E. Townsend, L. Allegra, R. J. Dutton, and S. A. Kriner, "Hot-dip coated sheet steels-a review," Materials Performance, vol. 25, no. 8, pp. 36-46, 1986.

[42] H. E. Townsend and A. R. Borzillo, "Twenty-year atmospheric corrosion tests of hot-dip coated sheet steel," Materials Performance, vol. 26, no. 7, pp. 37-41, 1987.

[43] J. W. Spence, F. H. Haynie, F. W. Lipfert, S. D. Cramer, and L. G. McDonald, "Atmospheric corrosion model for galvanized steel structures," Corrosion, vol. 48, no. 12, pp. 1009-1019, 1992.

[44] I. W. Odnevall Wallinder, P. Verbiest, W. He, and C. Leygraf, "Effects of exposure direction and inclination of the runoff rates of zinc and copper roofs," Corrosion Science, vol. 42, no. 8, pp. 1471-1487, 2000.

[45] S. Bertling, I. Odnevall, C. Leygraf, and D. Berggren, "Environmental effects of zinc runoff from roofing materials- A new multidisciplinary approach," in Outdoor Atmospheric Corrosion, ASTM STP 1421, H. E. Townsend, Ed., pp. 200215, American Society for Testing and Materials International, West Conshohocken, Pa, USA, 2002.

[46] W. He, I. Odnevall, and C. Leygraf, "Runoff rates of zinc-a four-year field and laboratory study," in Outdoor Atmospheric Corrosion, ASTM STP 1421, H. E. Townsend, Ed., pp. 216229, American Society for Testing and Materials International, West Conshohocken, Pa, USA, 2002.

[47] J. H. Sullivan and D. A. Worsley, "Zinc runoff from galvanised steel materials exposed in industrial/marine environment," British Corrosion Journal, vol. 39, no. 4, pp. 282-288, 2002.

[48] S. Matthes, S. Cramer, S. Bullard, B. Covino, and G. Holcomb, "Atmospheric corrosion and precipitation runoff from zinc and zinc alloy surfaces," in Proceedings of the 58th Annual Conference Corrosion, NACE, 2003, Paper 03598.

[49] S. Jouen, B. Hannoyer, A. Barbier, J. Kasperek, and M. Jean, "A comparison of runoff rates between $\mathrm{Cu}, \mathrm{Ni}, \mathrm{Sn}$ and $\mathrm{Zn}$ in the first steps of exposition in a French industrial atmosphere," Materials Chemistry and Physics, vol. 85, no. 1, pp. 73-78, 2004.

[50] D. Reiss, B. Rihm, C. Thöni, and M. Faller, "Mapping stock at risk and release of zinc and copper in Switzerland-dose response functions for runoff rates derived from corrosion rate data," Water, Air, and Soil Pollution, vol. 159, no. 1, pp. 101$113,2004$.

[51] R. M. Kain and E. A. Baker, ASTM STP 947, ASTM, Philadelphia, Pa, USA, 1986.

[52] S. H. Zhang and S. B. Lyon, "The electrochemistry of iron, zinc and copper in thin layer electrolytes," Corrosion Science, vol. 35, no. 1-4, pp. 713-718, 1993.

[53] A. Meneses Garcia, J. Rodarte Corro, O. Vidal Gutierrez, and E. Gonzalez Guzman, "The Mexican National Cancer Institute: case report," Revista del Instituto Nacional de Cancerologia, vol. 36, no. 4, pp. 1179-1182, 1990.

[54] M. Pourbaix, Atlas of Electrochemical Equilibria in Aqueous Solutions, NACE, Houston, Tex, USA, 1974. 
[55] E. A. Sacco, J. D. Culcasi, C. I. Elsner, and A. R. di Sarli, "Evaluation of the protective performance of several duplex systems exposed to industrial atmosphere," Latin American Applied Research, vol. 32, no. 4, pp. 307-311, 2002.

[56] J. M. Costa and M. Vilarrasa, "Effect of air pollution on atmospheric corrosion of zinc," British Corrosion Journal, vol. 28, no. 2, pp. 117-120, 1993.

[57] M. W. Kendig, A. T. Allen, and F. Mansfeld, "Optimized collection of ac impedance data," Journal of the Electrochemical Society, vol. 131, no. 4, pp. 935-936, 1984.

[58] J. Wolstenholme, "Electrochemical methods of assessing the corrosion of painted metals-a review," Corrosion Science, vol. 13, no. 7, pp. 521-530, 1973.

[59] R. A. Armas, C. Gervasi, A. R. di Sarli, S. G. Real, and J. R. Vilche, "Zinc-rich paints on steels in artificial seawater by electrochemical impedance spectroscopy," Corrosion, vol. 48, no. 5, pp. 379-383, 1992.

[60] J. E. O. Mayne, "The mechanism of the inhibition of the corrosion of iron and steel by means of paint," Official Digest, vol. 24, pp. 127-136, 1952.

[61] L. Meszáros and S. A. Lindquist, "Study of the performance of zinc-rich paints coatings," in Proceedings of the 115th Event of the European Federation of Corrosion (EUROCORR '82), pp. 147-156, Budapest, Hungary, October 1982, Section 11.

[62] M. Morcillo, R. Barajas, S. Feliu, and J. M. Bastidas, "A SEM study on the galvanic protection of zinc-rich paints," Journal of Materials Science, vol. 25, no. 5, pp. 2441-2446, 1990.

[63] B. del Amo, L. Véleva, A. R. di Sarli, and C. I. Elsner, "Performance of coated steel systems exposed to different media: part I. Painted galvanized steel," Progress in Organic Coatings, vol. 50, no. 3, pp. 179-192, 2004.

[64] O. Ferraz, E. Cavalcanti, and A. R. di Sarli, "The characterization of protective properties for some naval steel/polimeric coating/3\% $\mathrm{NaCl}$ solution systems by EIS and visual assessment," Corrosion Science, vol. 37, no. 8, pp. 1267-1280, 1995.

[65] P. R. Seré, D. M. Santágata, C. I. Elsner, and A. R. di Sarli, "The influence of the method of application of the paint on the corrosion of the substrate as assessed by ASTM and electrochemical method," Surface Coatings International, vol. 81, no. 3, pp. 128-134, 1998.

[66] D. M. Santágata, P. R. Seré, C. I. Elsner, and A. R. di Sarli, "Evaluation of the surface treatment effect on the corrosion performance of paint coated carbon steel," Progress in Organic Coatings, vol. 33, no. 1, pp. 44-54, 1998.

[67] P. R. Seré, A. R. Armas, C. I. Elsner, and A. R. di Sarli, “The surface condition effect on adhesion and corrosion resistance of carbon steel/chlorinated rubber/artificial sea water systems," Corrosion Science, vol. 38, no. 6, pp. 853-866, 1996.

[68] H. Leidheiser Jr. and M. W. Kendig, "Mechanism of corrosion of polybutadiene-coated steel in aerated sodium chloride," Corrosion, vol. 32, no. 2, pp. 69-75, 1976.

[69] T. Szauer and A. Brandt, "Impedance measurements on zincrich paints," Journal of the Oil and Colour Chemists' Association, vol. 67, pp. 13-17, 1984.

[70] D. J. Frydrych, G. C. Farrington, and H. E. Townsend, "The barrier properties of thin carbonaceous films formed by ion beam assisted deposition," in Corrosion Protection by Organic Coatings, M. W. Kendig and H. Leidheiser Jr., Eds., vol. 87-2, p. 240, The Electrochemical Society, Pennington, NJ, USA, 1987.

[71] E. P. M. van Westing, G. M. Ferrari, F. M. Geenen, and J. H. W. van de Wit, "In situ determination of the loss of adhesion of barrier epoxy coatings using electrochemical impedance spectroscopy," Progress in Organic Coatings, vol. 23, no. 1, pp. 89-103, 1993. 

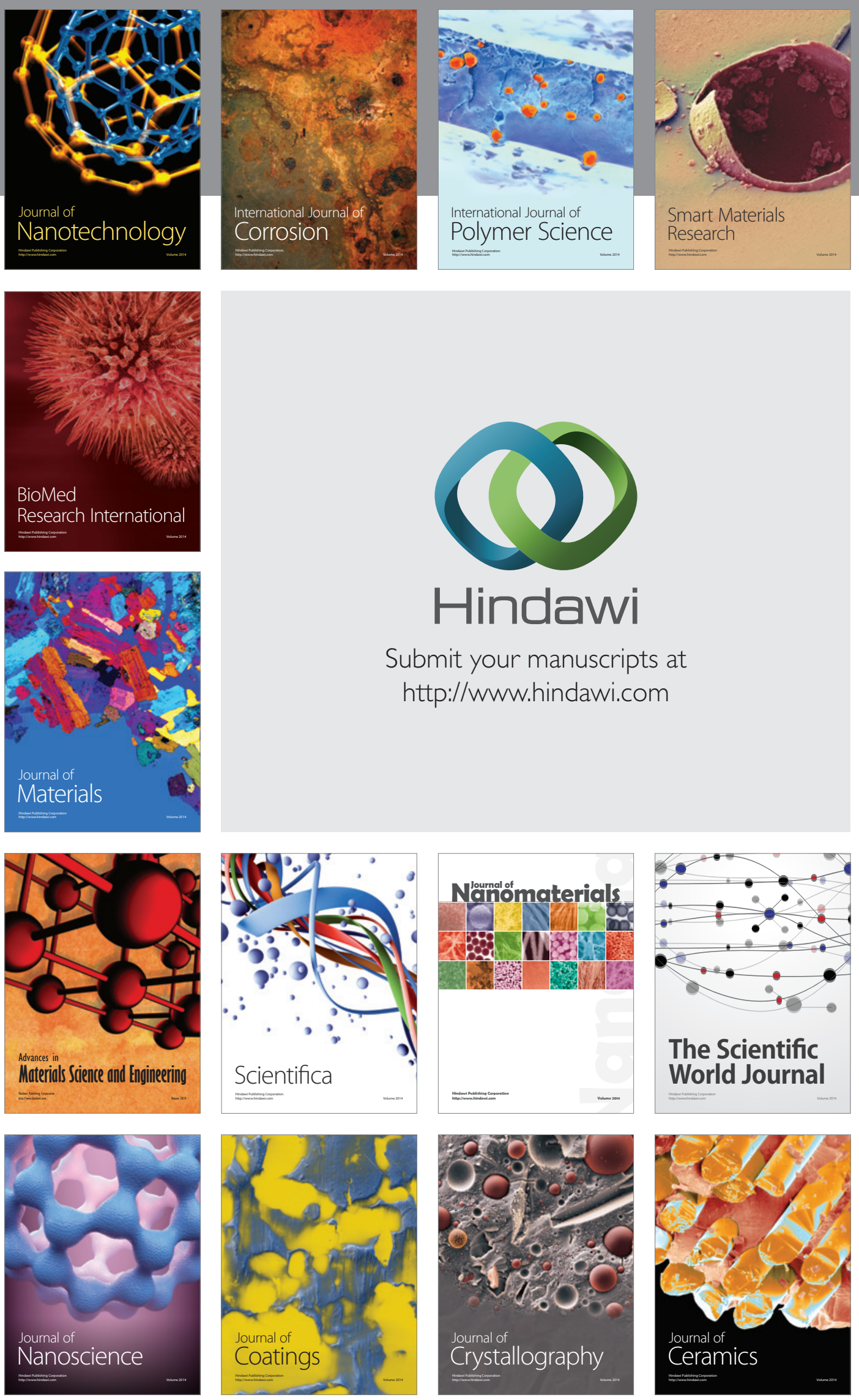

The Scientific World Journal

Submit your manuscripts at

http://www.hindawi.com

\section{World Journal}

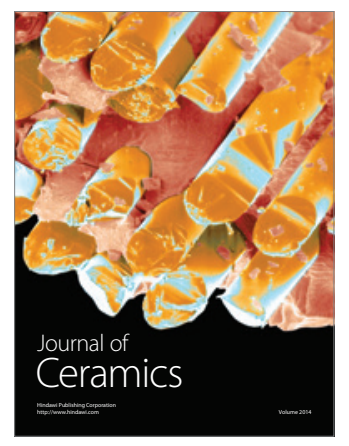

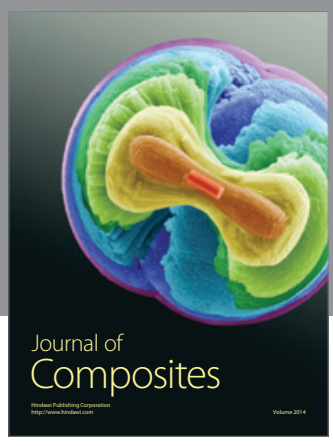
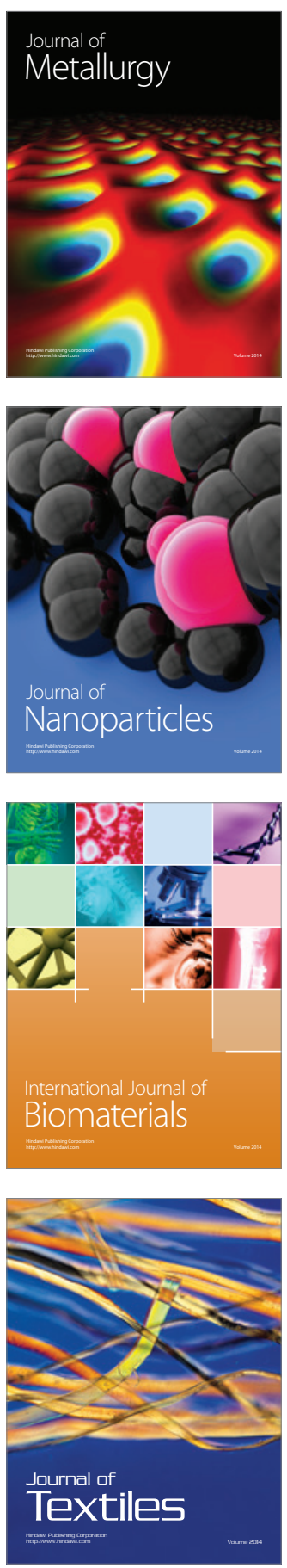